\title{
DO APARTHEID AO ESTALO: DISPUTAS IDEOLÓGICAS NA EDUCAÇÃO JURÍDICA
}

Ana Lia Almeida ${ }^{1}$

\begin{abstract}
RESUMO
Sintetizo aqui as ideias apresentadas no debate "Os desafios e as perspectivas do ensino jurídico no semiárido brasileiro", em 11 de agosto de 2020, a convite da equipe da Revista Estudantil Manus Iuris (REMI) devido ao lançamento da mesma. O objetivo volta-se à articulação de três aspectos do debate; a) as relações entre direito e ideologia; b) uma caracterização da ideologia do positivismo jurídico; e c) as possibilidades de enfrentamento ideológico na educação jurídica. O solo teórico da discussão apresenta-se em diálogo com certas formulações da tradição crítica ao direito a partir de categorias da tradição marxista.
\end{abstract}

Palavras-chave: Direito; Educação Jurídica; Ideologia.

\section{DO APARTHEID AO ESTALO: DISPUTAS IDEOLÓGICAS NA EDUCAÇÃO JURÍDICA}

Se você fosse um juiz na época do apartheid sul-africano e tivesse que julgar o crime de uma pessoa negra ter utilizado um ônibus destinado às brancas, você condenaria esta pessoa? Esta pergunta foi feita a uma turma de ingressantes no curso de direito de uma universidade pública no Brasil no início deste século XXI, e, para a surpresa e decepção do estudante que me contava esta história ${ }^{2}$, quase toda a sua turma respondeu que sim, condenaria a pessoa negra.

Esse tipo de história, infelizmente, poderia ter ocorrido em qualquer outra faculdade de direito do país, pois em geral são ambientes bastante elitizados e embranquecidos onde costumam imperar a acriticidade e o dogmatismo, dominados por uma orientação ideológica de conservação da ordem articulada a partir da desigualdade de classes, do racismo e do sexismo. A mesma caracterização pode ser ampliada para o campo jurídico como um todo, não se restringindo apenas ao âmbito da educação jurídica, tendo em vista os laços constitutivos e inescapáveis da forma jurídica com a sociedade de classes e suas relações conflituosas de gênero, sexualidade e raça.

\footnotetext{
${ }^{1}$ Ana Lia Almeida é professora da Universidade Federal da Paraíba, doutora em Direito e hoje docente do Programa de PósGraduação em Ciências Jurídicas da mesma instituição, onde também coordena o Núcleo de Extensão Popular Flor de Mandacaru e projeto de pesquisa no campo da crítica marxista ao direito. Associada ao Instituto de Pesquisa Direitos e Movimentos Sociais (IPDMS).

${ }^{2} \mathrm{O}$ relato foi colhido em pesquisa de campo para a tese de doutorado "Um estalo nas faculdades de direito: perspectivas ideológicas da assessoria jurídica universitária popular"(ALMEIDA: 2015)
} 
Tal maneira de compreender o direito e a educação jurídica permite a alusão metafórica ao apartheid, um regime que autorizava explicitamente a violência da segregação racial. A forma jurídica, por sua vez, a despeito das suas pretensões de universalidade, também autoriza formas de segregação legitimadas pela sociedade de classes. Evidentemente trata-se apenas de uma metáfora sem tanto rigor analítico, até mesmo porque o próprio regime de apartheid apresentava-se como parte da forma jurídica - o apartheid era o direito -, e também porque é questionável a comparação entre a segregação explícita daquele regime e as desigualdades sociais que convivem com o direito em geral de modo mais sofisticado e contraditório.

Aproximo metaforicamente a forma jurídica do regime do apartheid para fazer uso da expressão apartheid do direito, isto é, o direito como regime de apartheid, aludindo ao campo jurídico como um complexo que articula a segregação social.

No entanto, assim como o regime do apartheid sulafricano foi obstinadamente contestado pelos sujeitos históricos que buscava subjugar até a sua queda, no apartheid do direito também se inscrevem alguns enfrentamentos. Tais enfrentamentos somente são possíveis devido às contradições da totalidade histórica de que o complexo jurídico é parte, entrecortadas pela luta entre as classes e os grupos sociais. Os sujeitos que se embatem nessas lutas são mobilizados pelas ideologias, e no apartheid do direito também não é diferente. Contra a ideologia dominante se insurgem alguns sujeitos marginais a partir de certas iniciativas presentes no campo jurídico.

Uma destas iniciativas provocou um estalo para outro estudante de direito com quem conversei. Contou-me que, ao ingressar em um grupo de assessoria jurídica universitária popular na sua faculdade de direito, ocorreu um estalo em sua cabeça, pois ele mudou completamente o seu posicionamento sobre certas questões sociais. Ao lado dos movimento sociais com os quais passou a ter contato em virtude das atividades do grupo, passou a defender os seus direitos e tomar partido em suas lutas.

Cabe aqui refletir a respeito de alguns aspectos desses embates ideológicos que provocam estalos no apartheid do direito. Primeiro, tematizo as relações existentes entre direito e ideologia, delimitando o uso que faço dessa noção. Segundo, apresento uma caracterização do positivismo jurídico como ideologia dominante no direito. Terceiro, problematizo as possibilidades de enfrentamento ideológico na educação jurídica.

\section{DIREITO E IDEOLOGIA}

Ideologia é um termo que possui vários significados, sendo difícil encontrar um denominador comum que os reúna. A noção é bastante elástica e por vezes denota processos distintos, a depender da abordagem teórica a partir da qual seja tematizada.

Utilizamos o termo ideologia conforme a definição de István Meszáros, ou seja, como uma “consciência prática da sociedade de classes” (MÉSZÁROS:2004). Segundo ele, a ideologia consiste em uma "forma específica de consciência social, materialmente ancorada e sustentada", e não um problema individual de sujeitos iludidos ou enganados. Sendo uma “consciência prática inevitável” das sociedades de classes, está 
relacionada "com a articulação de conjuntos de valores e estratégias rivais que tentam controlar o metabolismo social em todos os seus principais aspectos” (MÉSZÁROS, 2004, p.65).

Esta abordagem recusa a identificação da ideologia como uma "falsa consciência" e deixa um pouco de lado a oposição entre "ideologia" e "conhecimento verdadeiro" para centrar o seu foco na compreensão das funções que as ideologias exercem na realidade social. Outro aspecto dessa abordagem é a consideração de que os processos ideológicos tanto podem se dar no intuito conservador da ordem como no âmbito da contestação da mesma. De uma forma ou de outra, o que as caracteriza como ideologia é o fato de estarem voltadas à ação prática.

Ao compreender ideologia como consciência prática da sociedade de classes, entendemos que o complexo jurídico situa-se por completo no campo das ideologias. O direito é ideologia não porque as representações jurídicas distorçam a realidade, consistindo numa "falsa consciência" para encobrir a dominação de classes. O que faz do direito ideologia é a sua capacidade de regulação prática das contradições sociais, tornando esse complexo indispensável para a reprodução da sociedade de classes. A mediação jurídica tem, portanto, um “objetivo prático" que consiste em "garantir a marcha da produção e da reprodução social" "PACHUKANIS: 1988, p.13). Por meio de seus especialistas, o direito opera eficazmente a força e o consenso necessários para garantir a continuidade do tipo de sociedade da qual ele se originou, e o faz tanto melhor quanto mais for capaz de desenvolver suas particularidades de modo relativamente independente em relação aos demais complexos da vida social.

Tal regulação prática exercida pelo direito exige uma técnica de manipulação bem peculiar, como aponta Lukács (2013, p.247), o que “já basta para explicar o fato de que esse complexo só é capaz de se reproduzir se a sociedade renovar constantemente a produção dos 'especialistas' (de juízes e advogados até policiais e carrascos) necessários para tal".

Portanto, a questão da formação dos juristas - os especialistas do direito - se situa dentro do problema da reprodução do complexo jurídico, que, por sua vez, é absolutamente indispensável para a reprodução da totalidade do ser social no modo como ele se caracteriza nas sociedades de classe. A educação jurídica é, em si, um complexo particular, que se articula com o direito e também com a educação. Por mais que se insista em reivindicar a neutralidade ou a imparcialidade desses dois complexos, o direito e a escola são espaços fundamentalmente importantes por meio dos quais os sujeitos tornam-se conscientes dos antagonismos da sociedade e orientam a sua ação tomando partido nesses antagonismos.

\section{O APARTHEID DO DIREITO E A IDEOLOGIA DO POSITIVISMO JURÍDICO}

O modo como o direito se reproduz na formação de seus especialistas foi objeto de análise de muitos dos teóricos brasileiros ligados à tradição da crítica jurídica. É o caso de Roberto Lyra Filho, Roberto Aguiar,

\footnotetext{
3 Pachukanis negou explicitamente o caráter "ideológico" da forma jurídica em "Teoria geral do direito e marxismo", argumentando que o direito não consistia numa "ilusão" que a burguesia buscava imprimir na sociedade com a intenção de garantir a dominação de classe. Reside aqui uma recusa ao sentido de ideologia como "falsa consciência", indicando, por outro lado, a plena compatibilidade das formulações pachukanianas com a abordagem da ideologia como uma "consciência prática".
} 
Fernando Coelho, José Geraldo de Souza Júnior, Maria Inês Porto, entre tantos outros. Uma das formulações mais difundidas, a de Luís Alberto Warat, identificou a existência do que denominou de "senso comum teórico dos juristas", uma espécie de pano de fundo das atividades cotidianas dos juristas, "uma para-linguagem, alguma coisa que está mais além dos significados para estabelecer em forma velada a realidade jurídica dominante" (WARAT, 1994, p.15). O núcleo desse "senso comum" consistiria na visão dogmática a respeito do direito, concebida como um sistema lógico-dedutivo centrado na lei, por sua vez considerada ideologicamente neutra.

Portanto, a produção dos especialistas necessários à reprodução do complexo jurídico ocorre por meio de alguns elementos centrais que se expressam de forma tão evidente e objetiva que foram apreendidos sem maiores discordâncias por teóricos ligados a diferentes tradições analíticas. Não pretendo apresentar uma nova sistematização dos elementos centrais da educação jurídica. Conforme muitos já notaram, eles consistem num evidente compromisso de classe dissimulado na reivindicação da "autonomia" e da "neutralidade" do direito, no estímulo a um racionalismo abstrato e retórico, na difusão de um dogmatismo manualesco como modo privilegiado de estudo etc. O liberalismo é a orientação ideológica que conduz todos esses aspectos da formação dos especialistas do direito, com algumas especificidade em relação à tradição liberal dos países capitalistas centrais.

As ideias que surgiram como uma novidade histórica no séc. XIX (positivismo, naturalismo, evolucionismo) se traduziram de acordo com "ridículos particulares" no Brasil, conferindo um "quê gratuito, incongruente e iníquo" ao ideário liberal (SCHWARTZ, 2000).

Valores como "impessoalidade" e "objetividade", aparentemente centrais para o liberalismo, subordinavam-se completamente à fantasia individual e aos caprichos das elites brasileiras, apresentando-se como “ideias fora do lugar” (SCHWARTZ,1999).

Contudo, estas ideias fora do lugar devem ser situadas a partir das funções sociais que exercem implicada na posição periférica que o Brasil e América Latina historicamente vêm ocupando na divisão internacional do trabalho.

Como nos ensina Florestan Fernandes (2009), as especificidades da conformação da democracia liberal no Brasil e na América Latina, personalista e conservadora como as classes dominantes que aqui residem, associam-se ao desenvolvimento dependente do capitalismo que se consolidou na região. Democracia e servidão, escravidão e trabalho livre, este complemento entre instituições burguesas e coloniais marca a história das ex-colônias latino-americanas em geral. Esta dinâmica jamais foi estranha para a ordem capitalista, sendo antes maneira de integrar a periferia do capital ao processo de acumulação produtiva no seu centro europeu. Desta implicação mútua e contraditória entre "progresso" e "atraso" resulta uma "modernização do arcaico" simultânea a uma "arcaicização do moderno", como nos ensinou Florestan Fernandes.

As configurações do positivismo jurídico no Brasil não escapam a este contexto do capitalismo 
periférico, conformando devidas adaptações necessárias ao atendimento de funções peculiares (ALMEIDA: 2015 e 2017):

De fato, o direito que se constituiu aqui apresenta especificidades em relação à forma jurídica alcançada sob as aspirações da burguesia dos países dirigentes do capitalismo de acordo com a ideologia liberal dos séculos XVIII e XIX. A defesa da propriedade privada e da liberdade de comércio, a igualdade perante a lei e a impessoalidade supostamente capazes de "neutralizar" os juízos de valor no trato com a coisa pública, todos esses valores adquiriram significados peculiares em solo brasileiro (ALMEIDA:2015).

Na expressão de Ricardo Pazello (2015), com as quais temos acordo, estas conformações particulares nos permitem observar a configuração de uma "forma jurídica periférica" no contexto do capitalismo dependente. Esta forma específica por meio da qual o direito se desenvolveu entre nós depende de certo modelo de educação jurídica para se reproduzir a partir da formação dos seus especialistas, por isso nas faculdades de direito tem tão largo alcance a ideologia do positivismo jurídico periférico.

\section{CONSIDERAÇÕES FINAIS: AS POSSIBILIDADES DE ESTALOS E ENFRENTAMENTO IDEOLÓGICO NAEDUCAÇÃOJURÍDICA}

A função da educação jurídica consiste, portanto, na reprodução de um direito supostamente "neutro" e "independente", ensinado abstrata e retoricamente por meio de um dogmatismo manualesco, movido por uma consciência prática liberal-periférica, no caso do Brasil. Mas como escapar a este modelo?

Compreendo que não é possível escapar dele somente a partir de iniciativas educativas, sem uma mudança global e profunda na ordem posta. Esta mudança, inclusive, implica nas possibilidades de superação da própria forma jurídica como um momento determinado historicamente na regulação das relações sociais. "Direito" e "educação jurídica", como formas da sociedade de classes, devem sua existência histórica a essa formação social no interior da qual se desenvolveram tendo, portanto, compromissos constitutivos e inescapáveis com a exploração.

No entanto, é sempre a partir das contradições de uma formação histórica que outra nasce e se desenvolve a ponto de romper com a anterior. Foi assim o rompimento da nascente sociedade capitalista com o regime feudal do qual ela se originou, assim também ocorrerá com novas formações históricas vindouras que certamente ficarão no lugar do capitalismo, ainda que possam apresentar arranjos ainda mais violentos e exploratórios.

Esses movimentos históricos são prenhes de estalos e disputas ideológicas. Em cada complexo da vida social é possível notá-los, se observamos bem, e identificar as lutas por trás deles. Olhando para o complexo jurídico, estes enfrentamentos estiveram desde muito cedo demarcados no contexto brasileiro apartir das lutas contra a escravidão, produzindo sujeitos como Esperança Garcia (Séc. XVIII) e Luíz Gama (Séc. XIX), por exemplo. Nos enfrentamentos da ditadura civil-militar brasileira do séc. XX (décadas de 60- 
80), advogados (as) e estudantes de direito desde o início se apresentaram. No período da redemocratização, organizações estudantis, de advogados(as), de juízes e sujeitos em geral do campo jurídico puderam se articular em torno do apoio às lutas sociais de uma maneira mais fortalecida.

No momento presente nos cabe mapear essas experiências e possibilitar pontes entre elas para que se fortaleçam em um período de grave ataque aos direitos das classes populares. A universidade, com sua conturbada experiência democrática, assume um lugar importante de resistência nesse cenário histórico. Nos cursos de direito podemos encontrar projetos de extensão, de pesquisa, centros de referência, núcleos de prática jurídica, escritórios-modelo, coletivos estudantis, atividades as mais diversas que reúnem estudantes e professores em torno da defesa das classes populares e dos direitos humanos.

Certamente a Revista Estudantil Manu Iuris é uma dessas experiências, um desses estalos nas faculdades de direito que reúne estudantes ocupados com o apoio às lutas sociais no campo jurídico no contexto do semi-árido do nordeste brasileiro. Que cresçam e frutifiquem. Vida longa à REMI!

\section{REFERÊNCIAS BIBLIOGRÁFICAS}

ALMEIDA, Ana Lia. UM ESTALO NAS FACULDADES DE DIREITO: perspectivas ideológicas da Assessoria Jurídica Universitária Popular. Tese (Doutorado) - UFPB/CCJ. João Pessoa, 2015.

ALMEIDA, Ana Lia. O Papel das Ideologias na Formação do Campo Jurídico. Revista Direito e Práxis, vol. 5, n. 9, pp. 34-59. Rio de Janeiro, 2014.

FERNANDES, Florestan. Capitalismo dependente e classes sociais na América Latina. São Paulo: Global, 2009.

LUKÁCS, Gyorgy. Para uma ontologia do ser social - vol.2. Tradução de Nélio Schneider, Ivo Tonet e Ronaldo Vielmi Fortes. $1^{\text {a }}$ edição. São Paulo: Boitempo, 2013.

MÉSZÁROS, István. O poder da ideologia. Tradução de Paulo Cézar Castanheira. São Paulo: Boitempo, 2004.

PACHUKANIS, E. B. Teoria Geral do Direito e Marxismo. São Paulo: Ed. Acadêmica, 1988.

PAZELLO, Ricardo. Direito insurgente e movimentos populares: o giro descolonial do poder e a crítica marxista ao direito. 2014. 545 fls. Tese (Doutorado em Direito). Universidade Federal do Paraná. CuritibaPR. 